\title{
Reuna
}

\section{DECISÃO ESTRATÉGICA EM EQUIPE DE DIREÇÃO: APRENDIZAGEM ALIADA AO CONFLITO}

\section{STRATEGIC DECISION IN DIRECTIVE TEAM: LEARNING ALLIED TO CONFLICT}

\author{
http://dx.doi.org/10.21714/2179-8834/2019v24n4p84-105
}

Tatiane Silva Tavares Maia

Universidade Federal de Mato Grosso do Sul (UFMS), Brasil.

E-mail: tstavares@gmail.com

Edmilson de Oliveira Lima

Universidade Nove de Julho de São Paulo (UNINOVE), Brasil.

E-mail: edmilsonolima@uni9.pro.br

Submissão: 16 Jun. 2017 Publicação: 21 Dez. 2019. Sistema de avaliação: Double blind review. Centro Universitário UNA, Belo Horizonte - MG, Brasil. Editor chefe: Prof. Dr. Gustavo Quiroga Souki

Este artigo encontra-se disponível nos seguintes endereços eletrônicos:

http://revistas.una.br/index.php/reuna/article/view/944

http://dx.doi.org/10.21714/2179-8834/2019v24n4p84-105

\section{Resumo}

O estudo apresentado objetivou gerar conhecimentos sobre o processo de decisão estratégica realizado por uma equipe de direção em pequenas empresas (PE), focando principalmente os processos de aprendizagem em circuito duplo e de conflito cognitivo. A abordagem metodológica é de estudo de caso qualitativo. A coleta dos dados baseou-se em entrevistas em profundidade com membros da equipe e, as análises de dados, na consideração detalhada de parcelas de conteúdo com o software de análise Atlas-ti. Os resultados da pesquisa mostram que o conflito cognitivo desviou as tomadas de decisão da intuição e da improvisação, pois provocou discussões, análises e reflexões coletivas. A aprendizagem em circuito duplo ocorrida por influência do conflito cognitivo incluiu o questionamento das possibilidades, rico e propício à melhoria da tomada de decisão.

Palavras-chave: Aprendizagem em Circuito Duplo. Conflito Cognitivo. Decisão Estratégica. Equipe de Direção. Pequenas Empresas.

\section{Abstract}

The study presented here aimed to generate knowledge about the strategic decision process carried out by a management team in small companies (PE), focusing mainly on the processes of learning in double circuit and cognitive conflict. The methodological approach is a qualitative case study. Data collection was based on indepth interviews with team members and, data analysis, on detailed consideration of content plots with Atlas-ti analysis software. The results of the research show that cognitive conflict diverted decision-making from intuition and improvisation, as it provoked discussions, analyzes and collective reflections. The double circuit learning that occurred due to the influence of cognitive conflict included the questioning of possibilities, rich and conducive to improved decision making.

Keywords: Double-Loop Learning. Cognitive Conflict. Strategic Decision. Direction Teams. Small Firm. 


\section{Introdução}

Muitas pequenas empresas (PEs) são fundadas e administradas por equipes de direção. Tais equipes realizam os processos de decisão estratégica (PDE) e ajudam a superar as dificuldades das PEs e a mutuamente somar seus conhecimentos e competências em benefício da gestão. Uma definição clássica e simples de equipes de direção diz que são coletividades compostas de pessoas unidas e interdependentes com a finalidade de realizar atividades em conjunto na direção de uma organização (HAMBRICK, 1995). Por sua vez, a equipe de direção de PE é entendida aqui como a equipe formada por coproprietários-dirigentes atuantes nos processos de decisão estratégica, atores denominados codirigentes (LIMA, 2012).

No trabalho coletivo experimentado por esse tipo de equipe, o conflito do tipo cognitivo pode surgir com certa facilidade e gerar benefícios para a organização por comportar diferenças de perspectiva e de ideias, normalmente debatidas em processos de decisão estratégica (LOUGHRY; AMAZON, 2014; HJERTO; KUVAAS, 2017). O conflito cognitivo refere-se à interação entre dois ou mais indivíduos com ideias diferentes a respeito de qual rumo dar aos negócios, indivíduos que, a partir de tal interação, sintetizam pontos de vista úteis para a tomada de decisão (JEHN et al., 2008, LOUGHRY; AMAZON, 2014; MELLO; DELISE, 2015; HJERTO; KUVAAS, 2017). O confronto de ideias do conflito cognitivo oportuniza a aprendizagem em circuito duplo. Devido aos efeitos potencialmente benéficos do conflito cognitivo e à carência de mais conhecimento detalhado sobre sua ocorrência, em especial nas PEs e nos processos de decisão estratégica, seu estudo aprofundado em novas pesquisas é particularmente recomendável (BEHFAR et al., 2011; TJOSVOLD et al., 2014; WEINGART et al., 2015).

Adicionalmente, acredita-se que a aprendizagem nutrida até mesmo por aspectos alheios à racionalidade formal seja muito relevante para a decisão estratégica em PE e carece de estudo mais detalhado (WYER et al., 2000; LIMA, 2012). $\mathrm{Na}$ literatura acadêmica, encontram-se poucas pesquisas sobre aprendizagem em estratégia de PE que descortinam como se aprende quando das decisões estratégicas realizadas por uma equipe de direção de modo a se obter melhores condições para se decidir.

Estudar a aprendizagem ocorrida na interação entre codirigentes em situação de decisão estratégica, seguindo os pressupostos teóricos da aprendizagem em circuito duplo (ARGYRIS; SCHON, 1978), explora uma associação teórica que não tem sido usada nas pesquisas sobre as PEs - fato que ajuda a caracterizar um potencial promissor de contribuição de tal estudo. Tal estudo ajuda a superar a necessidade de se pesquisar mais detalhadamente a gestão estratégica das PEs. Ademais, ele também ajuda a atender a necessidade de mais pesquisas para se investigar especificamente a aprendizagem em circuito duplo (CHASTON et al., 2001; MATTIA, 2011) e como ela ocorre entre os codirigentes e se compartilha nas equipes de direção (BRESMAN; ZELLMER-BRUHN, 2013; WOLFF et al., 2015; YOON et al., 2016). 


\section{A equipe de direção na PE}

$\mathrm{Na}$ PE a ideia de gestão por equipes se associa a elementos e situações próprios de sua realidade. Inclui a consideração das restrições típicas de recursos que essas empresas precisam superar, relacionados com as vendas e o marketing, o planejamento, a falta de experiência administrativa dos dirigentes e as restrições de recursos financeiros (FULLER-LOVE, 2006; GREENE et al., 2015; IBRAHIM, 2015). Nestas empresas não se espera encontrar estruturas organizacionais e procedimentos sofisticados (ESCRIBA-ESTEVE et al., 2009). Geralmente não há nelas recursos administrativos com folga ou sistemas de gestão avançados, comuns em grandes empresas, subsidiando seus processos decisórios; consequentemente, as PEs dependem mais das competências e capacidade de trabalho de seus proprietários-dirigentes (LUBATKIN et al., 2006; MAZZAROL; REBOUD, 2009).

A equipe de direção compõe-se de um número restrito de dirigentes numa organização, pessoas comprometidas com 0 atingimento dos objetivos da organização, dotadas de competências, conhecimentos e habilidades que tendem a ser complementares (KATZENBACH; SMITH, 2005; LIMA, 2012). Devido a sua variedade de competências, conhecimentos e habilidades tendente à complementaridade, quando comparadas à situação de um só dirigente à frente de uma organização, as equipes de direção normalmente apresentam melhor cobertura das diferentes áreas e necessidades de atividade da organização.

Nessas equipes acontecem as decisões estratégicas. Aspectos como a complementaridade e a colaboração, aliados à aprendizagem coletiva podem facilitar o processo de tomada de decisão dos codirigentes. Naturalmente, a ocorrência de conflitos cognitivos, com o embate de ideias e a expressão de pontos de vista diferentes, marca as decisões estratégicas, inclusive favorecendo a aprendizagem benéfica para tais decisões.

\section{Aprendizagem e conflito cognitivo na decisão estratégica de equipes de direção}

O interesse de pesquisadores pelo processo de decisão estratégica conduzido por uma equipe de direção em PE é recente. Evidencia-se pouco interesse, até o momento, pelo processo de aprendizagem em estratégia de PE, principalmente em conexão com equipes de direção. Contudo, quando os codirigentes aprendem coletivamente nas equipes, ampliam suas bases de conhecimento, desenvolvendo melhor a decisão estratégica. Daí, as características pessoais desses atores e suas preferências, aspectos que influenciam altamente na tomada de decisão estratégica, podem ser aproveitados para produzir melhor desempenho na PE (LIBERMAN-YACONI et al., 2010).

Na direção da PE, cada proprietário-dirigente é um ator importante e decisivo na configuração da gestão estratégica; de seu julgamento e de seu conhecimento depende fortemente o processo de tomada de decisão (EKANEM; SMALLBONE, 2007). Associados em uma equipe, os proprietários-dirigentes apresentam-se como codirigentes, os quais conduzem processos estratégicos que se constroem contando com a aprendizagem apoiada nas relações entre eles. Para promover a aprendizagem e a cooperação no ambiente organizacional, fazem-se necessárias as interações entre os codirigentes, apoiadas na troca de informações e ideias, nas 
relações de colaboração, na tomada de decisão conjunta e no compartilhamento de habilidades complementares (LUBATKIN et al., 2006).

Considerando o processo de aprendizagem em estratégia de PE, compreende-se que ele pode ser concebido como um processo estratégico na teoria de ação, proposta por Argyris e Schön (1978). Por meio dessa teoria há uma evidente conexão de dois campos de pesquisa, aprendizagem e estratégia. Tal conexão torna-se possível diante da principal proposta da teoria, a qual envolve eliminar rotinas defensivas que inibem o aprendizado organizacional por meio do mapeamento do comportamento humano (ARGYRIS, 2003). Por isso, seus pressupostos associam-se a mudanças profundas de pensamento, possibilitando descortinar a complementaridade entre os codirigentes e a tomada de decisão estratégica realizada em equipe.

Como a teoria da ação refere-se ao comportamento humano deliberado, aos padrões e intenções, pressupostos vigentes e normas que o indivíduo utiliza para determinar suas ações (GUNDERMAN; CHAN, 2007), especialmente sua abordagem da aprendizagem denominada circuito duplo. $O$ processo de aprendizagem por meio do circuito duplo é explicado por Argyris e Schön (1978) como um questionamento dos pressupostos vigentes que orientam a ação, o que possibilita a criação de novos conhecimentos e a reflexão sobre as possíveis inconsistências, o que também leva a mudanças de comportamento. Acredita-se que a aprendizagem em circuito duplo possa ajudar as organizações a aprender a se adaptarem, favorecendo o desenvolvimento da gestão (GUNDERMAN; CHAN, 2007; MATTIA, 2011). Aprender a descobrir como descobrir, inventar formas de descobrir, produzir invenções que levem ao descobrimento e generalização da aprendizagem criada (WATKINS; SHINDELL, 1994).

O processo de aprendizagem, tal como descrito acima, não está livre de conflitos, os quais, aliás, são inerentes à vida organizacional. A aprendizagem em circuito duplo se origina do conflito cognitivo, que pode ser considerado uma força poderosa, que as equipes de direção precisam enfrentar (MOONEY et al., 2007). Quando referente a questões decisórias, o conflito cognitivo além de natural é até mesmo necessário, a alternativa a ele geralmente não significa acordo ou harmonia, mas indícios de apatia do grupo e desengajamento (EISENHARDT et al., 1997).

O conflito do tipo cognitivo, interesse deste estudo, ocorre quando equipes discutem e debatem várias preferências, visões e opiniões sobre suas tarefas e, a partir disso conseguem sintetizar distintos pontos de vista (JEHN et al., 2008; HJERTO; KUVAAS, 2017). Geralmente essa modalidade de conflito melhora o processo de decisão estratégica e a qualidade dele, além de incentivar sua compreensão e aceitação, uma vez que é debatido em grupo (JEHN et al., 2008). Alguns pesquisadores reconhecem o conflito como uma importante dimensão, envolvida diretamente no sucesso de processos de decisões em equipes de direção (AMASON, 1996; MOONEY et al., 2007; OLSON et al., 2007). Essa defesa parece partir da noção de que a ampla participação no processo decisório é necessária para a sobrevivência e o crescimento organizacional, pois dela derivam as soluções criativas, as quais podem surgir de muitas fontes diferentes dentro da equipe.

Pelo que foi exposto sobre decisão, fica evidente que, de modo geral, o desenvolvimento do processo de decisão estratégica é favorecido pelo conflito cognitivo, na medida em que nesse processo esse conflito facilita a consideração de 
diferentes alternativas, a comunicação franca e aberta, melhora a qualidade das decisões e a sua aceitação entre os codirigentes, incentiva o pensamento inovador, promove soluções criativas para problemas que de outra forma poderiam parecer intransponíveis. Portanto, é importante incentivar o conflito cognitivo, já que pode promover a troca de ideias, o surgimento de hipóteses e a síntese de diversas perspectivas, resultando decisões mais equilibradas e bem fundamentadas no processo de decisão estratégica (MOONEY et al., 2007).

Alguns estudos confirmam que há um efeito positivo do conflito cognitivo no aprendizado (DE DREU, 2008; VAN WOERKOM; VAN ENGEN, 2009; BEHFAR et al., 2011; WOODS, 2012), despertando o interesse em compreender como a aprendizagem poderia se manifestar em processos de decisão estratégica em equipes, a partir desse tipo de conflito.

\section{Métodos}

A pesquisa se caracteriza como um estudo de caso de natureza qualitativa e envolve uma abordagem exploratório-descritiva. Seguindo a recomendação de Yin (2010) para construção de um caso, o início dessa pesquisa se baseou em uma versão preliminar de fundamentação teórica. Foram seguidos critérios mínimos estabelecidos para a escolha do caso, tais como, ser uma PE (até 49 empregados segundo o Serviço Brasileiro de Apoio às Micro e Pequenas Empresas, (SEBRAE, 2011), ser uma empresa dirigida por uma equipe de direção, ter no mínimo três anos de existência.

Os dados foram coletados por meio de entrevistas em profundidade, conduzidas por um roteiro semiestruturado, gravadas na sede da PE, com duração média de duas horas. Foram entrevistados três codirigentes, membros da equipe de direção e um funcionário (envolvido em processos de decisão estratégica). Foi feita uma suplementação de dados no processo de coleta por meio de análise documental. Foram utilizadas, essencialmente, informações da website, como base para essa análise e complemento aos relatos dos casos. Nos relatos dos codirigentes entrevistados foram identificadas decisões lá referenciadas, além de descrições sobre a trajetória histórica da PE.

Os codirigentes da jovem equipe têm entre 26 e 35 anos, são formados em análise de sistema e ciência da computação. Note-se que o nome da PE foi designado pela letra Delta do alfabeto grego. Ela foi fundada em 2010 na cidade de São Paulo. Atualmente conta com 23 funcionários e oferece como principais serviços consultorias para o desenvolvimento de sistema de informação.

O processo de análise combinou a descrição para organização dos dados e a interpretação para explicá-los em paralelo com a coleta, a interpretação, a construção teórica e a redação do caso. A análise foi operacionalizada atribuindo códigos às unidades de significação, contemplou fatores de destaque da aprendizagem e do conflito cognitivo que se repetiam nos processos de decisão estratégica. $O$ processo de análise foi facilitado por meio do software de pesquisa qualitativa ATLAS/ Ti. O processo de construção de teorias com uso do ATLAS/ti envolveu as seguintes operações básicas: codificação (abstração) e rotulação dos dados; realização de microanálise dos dados; identificação e validação de categorias (BANDEIRA-DE-MELLO, 2006). 


\section{Apresentação e análise dos dados}

A Delta foi fundada no ano de 2010, mas anteriormente sua equipe de direção já havia dado os primeiros passos no trabalho conjunto para criar um produto, o qual levaria à formalização dessa equipe e à fundação da PE.

Ainda em situação informal, essa equipe criou um produto denominado Delta, a partir da constatação coletiva de insatisfação com os respectivos empregos. Dentre os codirigentes, dois eram sócios minoritários com uma pequena porcentagem na sociedade da empresa na qual trabalharam por mais de 10 anos. Nela ingressaram quando ainda era uma PE, depois cresceu e tornou-se demasiadamente burocratizada, daí os codirigentes sócios passaram a não concordar com a política de gestão instituída.

Dessa insatisfação e a partir de conversas informais, ocorreu a associação entre os codirigentes que, além de colegas de trabalho, eram dois grandes amigos. O codirigente três também partilhava as discordâncias e foi incluído logo em seguida na equipe de direção informal. Em face disso, no período de campanha das eleições presidenciais em 2010, primeira eleição no Brasil ocorrida com a utilização das redes sociais, uma das ideias que os codirigentes debateram foi desenvolver um produto para fazer monitoramento de marcas naquelas redes. O plano era oferecê-lo tanto para políticos como para empresas, inspirados na evidência de que o presidente Barack Obama havia sido reeleito nos Estados Unidos por ter se utilizado das redes sociais.

Esse produto foi desenvolvido rapidamente, em uma época em que surgiram várias ferramentas tecnológicas, as quais facilitavam o processo de criação. Diante disso, decidiram tornarem-se donos do próprio negócio, deixaram seus empregos e formalizaram a empresa. Dentro de três meses, os codirigentes conseguiram lançar o produto Delta. Nos primeiros meses se dedicaram à criação do mesmo, sem receberem qualquer remuneração. Houve ainda o esforço da equipe de investir suas rescisões contratuais, recurso recebido na saída dos empregos.

Com capital próprio e de modo improvisado, cada um trabalhava em sua residência e, na ausência do escritório, reuniões periódicas eram realizadas na garagem da casa do codirigente dois. Durante um período de cinco meses, os codirigentes se empenharam em vender o produto Delta e como não obtiveram sucesso, constataram que seria necessário buscar alternativas de sobrevivência para o negócio. Nessa primeira crise, identificaram os serviços de consultoria em sistema como possível solução, mas também perceberam as dificuldades de trabalhar nessa área.

A insegurança em atuar como prestadores de serviços foi vencida diante das dificuldades de manter a empresa. Os codirigentes necessitaram "virar a chave", expressão que utilizaram para explicar a transição do negócio de produto para projetos de consultoria, os quais, após o primeiro trabalho e por meio de contatos, trouxeram vários clientes, mais funcionários e outros tantos projetos.

A partir de então, os codirigentes conseguiram realmente se estabelecer. Segundo o codirigente três, o crescimento foi a colheita, ou seja, o resultado da dedicação e do empenho nos projetos: “...a gente foi plantando, porque querendo ou não essa área é muito pequena e as pessoas se conhecem, se você faz um trabalho 
bom ou um trabalho ruim esse trabalho depois acaba sendo refletido para outro cliente."

Com o crescimento da empresa em números de trabalhos executados e funcionários, surgiu a necessidade de alugar um escritório, onde já instalados e com a evolução das consultorias, os três codirigentes perceberam que elas poderiam ser mais bem elaboradas se houvesse desenvolvimento conceitual e teórico nos projetos. Identificaram a oportunidade de abrir a equipe de direção e incluir mais um membro que contribuísse justamente com esse requisito.

No ano de 2012 aconteceu então, a entrada de um novo sócio para complementar a equipe com uma perspectiva mais acadêmica dos sistemas. Houve uma redistribuição na composição societária, que passou a ser $30 \%$ para os codirigentes um e dois e $20 \%$ para os codirigentes três e quatro. Entretanto, no ano de 2014, em função das dificuldades de interação na equipe o novo codirigente deixou a sociedade. Conforme relato dos codirigentes entrevistados, houve muito desgaste no relacionamento da equipe, a sociedade chegou ao fim. A composição societária foi então reestabelecida.

Hoje são vinte e seis pessoas atuantes no desenvolvimento de softwares e na administração de projetos de sistemas. A filosofia de trabalho da Delta se baseia em entender a necessidade dos clientes e projetar a melhor solução de software, com respeito às tecnologias utilizadas e ao orçamento disponível. A ideia é resolver os problemas dos clientes, desde a concepção de um sistema novo até o "retorno aos trilhos" de um sistema problemático.

Em cinco anos de existência a empresa cresceu muito e a partir da criação do produto Delta os codirigentes ressaltaram as decisões fundamentais para que houvesse tamanho crescimento. Abandonar o produto Delta e apostar em consultorias de desenvolvimento de software foi uma delas, seguida do aperfeiçoamento na prestação de serviços, via design dos sistemas e as alterações na composição da equipe de direção, com entrada e saída de um codirigente.

Os processos de tais decisões foram estudados neste caso, alguns fatores de destaque presentes nos processos de decisão estratégica, relacionados com trechos de entrevistas analisados, esclarecem a fundamentação empírica de conflitos cognitivos e aprendizagem em circuito duplo, surgidos nesses processos.

Alguns fatores que apareceram com maior frequência serão apresentados e relacionados na figura 1 . 
Figura 1 - Fatores de destaque mais representativos dos processos de decisão estratégica

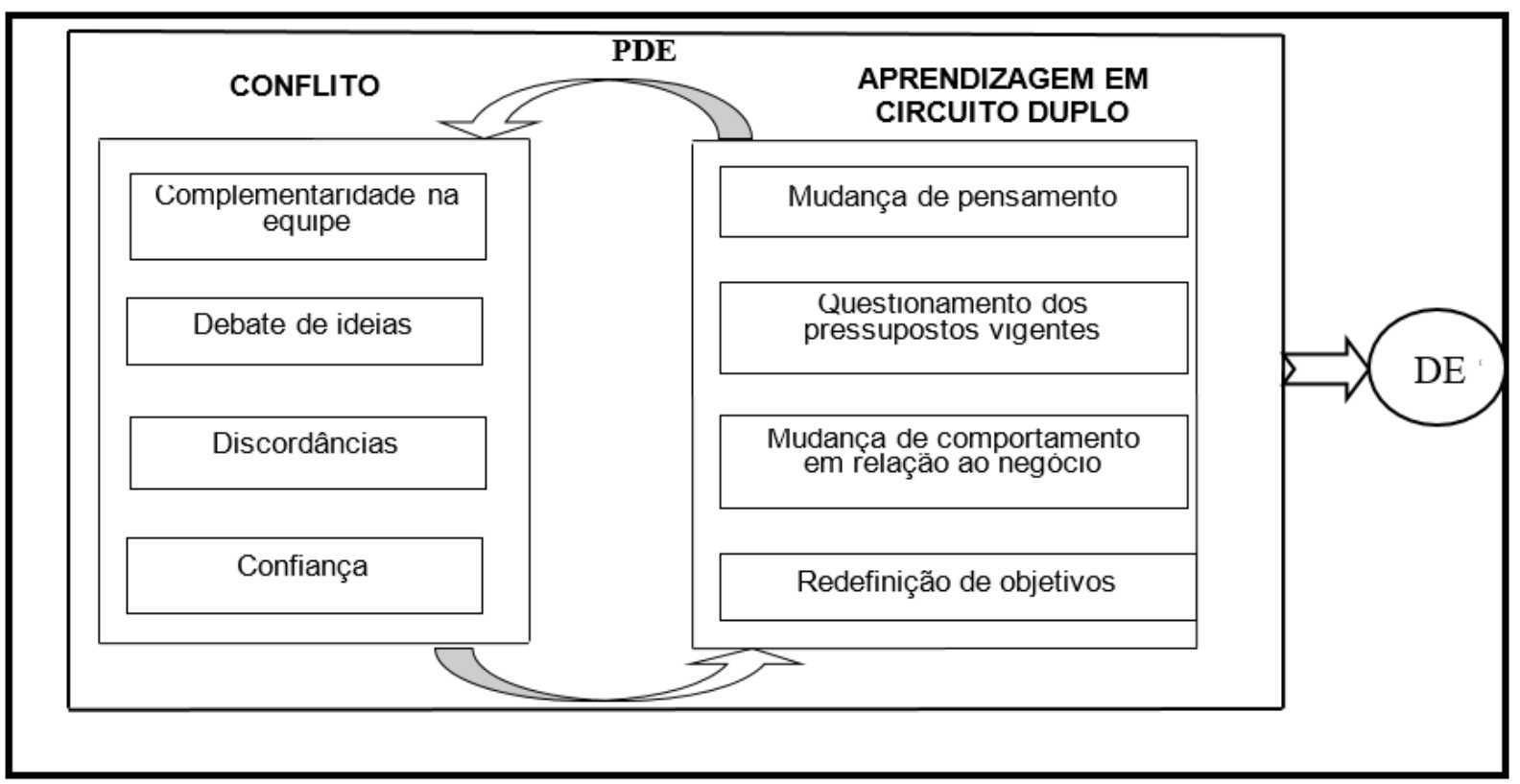

Fonte: Dados da pesquisa.

$\mathrm{Na}$ sequência serão explicados os diferentes fatores de destaque apresentados na figura 1 e estabelecidas as suas relações.

\subsection{Processos de decisão estratégica: interação entre os codirigentes e conflitos cognitivos}

As constatações empíricas permitiram confirmar que há presença de conflitos cognitivos nos processos de decisão estratégica realizados pelos codirigentes da Delta. A seguir, os principais fatores de destaque, mencionados na figura 1 serão discutidos, tendo em vista o processo de decisão estratégica no qual ele foi identificado e no decorrer da contextualização desse processo.

\subsubsection{Criação do produto Delta}

O primeiro processo de decisão estratégica identificado, a criação do produto Delta, foi realizado pelos três codirigentes, até então colegas de trabalho, que se demonstravam insatisfeitos com a filosofia de gestão da empresa em que trabalhavam. Após isso, fundaram o próprio negócio, amparados por propósitos bem específicos.

Pode-se constatar que foi a partir do choque de propósitos na condução das relações com clientes que, inicialmente, os codirigentes um e dois, grandes amigos, passaram a se reunir, ainda informalmente. Nas reuniões informais discutiam sobre as dificuldades de se manterem no emprego e acabaram ganhando como aliado o codirigente três. 
Nesse momento, os debates de ideias, fator de destaque do conflito cognitivo, impulsionaram fortemente o processo de decisão estratégica em equipe de desenvolver um produto e, consequentemente, deixar os empregos, fundar um negócio, no qual pudessem ter liberdade de criação. Eles debatiam sobre como criariam um produto, as alternativas e viabilidade técnica de criação do futuro produto Delta.

Os debates giravam em torno dessa viabilidade e também dos propósitos da nova empresa. Nela, pretendiam poder trabalhar e se divertirem ao mesmo tempo e ainda conservarem a postura transparente com os clientes. Conjuntamente e por considerarem todos esses aspectos, fundaram a empresa e tomaram a decisão estratégica de criar o produto.

Pode-se dizer que os debates para chegarem à ideia do produto original foi um rico exercício, no qual a equipe de direção pode começar a testar seu funcionamento antes da empresa formalizada. Além disso, consolidou a confiança, fator de destaque do conflito cognitivo essencial nesse processo, posto que impulsionou os codirigentes a enfrentarem os obstáculos e decidirem pelo início do desenvolvimento do produto.

A base da interação dos codirigentes já desde o princípio foi a confiança na relação como sócios e nas recíprocas habilidade e perícia técnica a ponto de mudarem os rumos de suas vidas apoiados um no outro, especialmente na relação entre os codirigentes um e dois, que trabalharam juntos por mais de dez anos.

Quando se tornaram uma equipe de direção formal, ainda sem nenhuma perspectiva quanto ao sucesso do produto, o processo de decisão fluiu à base de forte confiança mútua; afinal, os três codirigentes investiram no novo empreendimento toda a rescisão contratual do emprego que deixaram.

\subsubsection{Transição de produto para consultorias}

A criação do produto Delta muito contribuiu para consolidar a equipe de direção. A partir dele, os codirigentes deram um grande passo na formalização da empresa. Contudo, os resultados práticos dessa decisão foram frustrados e levaram os codirigentes à realização do segundo processo de decisão estratégica, a transição de produto para consultorias, e se tornarem uma empresa prestadora de serviços.

A empresa que nasceu focada em produtos precisou de uma mudança de rumos a partir do fracasso na comercialização do produto Delta. Houve o reconhecimento de que a comercialização do produto envolvia uma dinâmica muito diferente, enquanto a consultoria demanda maior número de pessoas para desenvolver os projetos. Contudo, a área foi identificada em um momento muito promissor, segundo os codirigentes. Em função da dificuldade de contratar profissionais de tecnologia da informação as empresas estavam optando por consultorias. Foi essa oportunidade que eles decidiram aproveitar também.

Além disso, o processo de decisão estratégica durou até o momento em que os codirigentes constataram, na primeira prestação de serviços, que por meio da consultoria poderiam conquistar o diferencial perseguido enquanto empresa. Nesse momento, intensificaram-se os debates de ideia, fator de destaque do conflito cognitivo que despertou para a possibilidade de manter a empresa apoiada em 
transparência, livre de qualquer politicagem e oferecer consultorias, embora não fossem tecnicamente os melhores.

Foi possível a percepção de que houve insegurança em abandonar o produto e partir para os serviços de consultoria, sobretudo, quando se questionavam: "será que a gente vai conseguir?". O primeiro projeto deu o subsídio necessário para, como disseram os codirigentes, "virar a chave" e tomarem a decisão estratégica.

Mas, nesse momento ainda houve discordâncias, fator de destaque do conflito cognitivo que, em equipe, impulsionou a transição para empresa de consultoria e ainda serviu para orientar a ação dos codirigentes para, diferentemente do resultado do produto, conseguirem se firmar nesse campo de atuação. Com intuito de buscar clientes e assumir novos projetos, os codirigentes começaram a contratar funcionários, montaram um escritório e estruturaram a empresa para consultorias.

\subsubsection{Exploração de diferencial no design de softwares}

Após tornar a Delta uma empresa de consultoria, os codirigentes começaram a estruturar a prestação de serviços e identificaram um diferencial nesse setor. Dele surgiu o terceiro processo de decisão estratégica: exploração de diferencial no design de software. Tal processo envolveu, além da melhoria na apresentação do sistema, a contratação de um profissional específico para trabalhar o design dos projetos.

Com a montagem do escritório da empresa, intensificaram-se os projetos de consultoria e a prestação de serviços seguia funcionando muito bem, por meio do trabalho dos desenvolvedores e programadores; entretanto, os codirigentes ainda se mostravam insatisfeitos com o aspecto visual do sistema, o qual impactava negativamente, inclusive no valor cobrado pelo software.

Apoiado pelo codirigente três, o codirigente um apontou primeiramente que faltava no desenvolvimento dos sistemas um trabalho de design para cuidar do layout, todavia a equipe não dispunha de competência suficiente para realizá-lo. As objeções apresentadas pelo codirigente dois enfatizaram a complementaridade na equipe, fator de destaque do conflito cognitivo que ajudou a ponderar esse processo de decisão estratégica.

A questão central passou então a ser o desafio de acomodar de modo satisfatório um novo profissional que pudesse, simultaneamente, agregar valor aos sistemas e promover a expansão e a melhoria na prestação de serviços realizados pela equipe. Contudo, surgiu outro fator de destaque relevante do conflito cognitivo, as discordâncias a respeito de como tais serviços deveriam ser esquematizados nos processos de desenvolvimentos dos projetos de consultoria.

Houve, especialmente por parte dos codirigentes um e três, a ambição de incrementar os serviços por meio do acabamento de design. O codirigente dois, mais conformado com o formato básico de prestação dos serviços, levantou os seguintes pontos de discordância: como entregar melhor os serviços? Ou seja, qual seria o esquema novo para isso? Quais seriam os efeitos colaterais? Tais pontos de discordâncias foram discutidos e resolvidos, demonstrando que a complementaridade, inclusive de pontos de vista, é favorável ao processo de decisão estratégica na equipe. 


\subsubsection{Entrada e saída de sócio na equipe de direção}

O quarto e último processo de decisão estratégica, concernente à entrada e posterior saída de um sócio na equipe de direção da Delta, relaciona-se com o ato de agregar mais um membro na equipe com o objetivo de elevar o nível conceitual e acadêmico dos projetos desenvolvidos.

Esse processo foi muito importante por retratar a consciência dos codirigentes de que suas formações precisariam de uma complementaridade na gestão, com vistas a melhor conduzir o negócio, assim como ela ocorria tão harmonicamente no âmbito de comportamentos e personalidades. Na Delta os papéis estavam definidos de maneira clara: o codirigente um, realizador de networking, cuidava das relações públicas e da área comercial, enquanto o codirigente dois era considerado o "cara carismático do RH" e, por fim o codirigente três, o mais competente na parte técnica.

A complementaridade, fator de destaque nesse processo de decisão estratégica, tanto no aspecto de trazer um novo membro para equipe como no momento de aceitar sua saída, foi forte e não se limitou ao campo de atividade. Trata-se da complementaridade de personalidade, um codirigente cuida da gestão de funcionários porque tem mais entrosamento com as pessoas, outro cuida da parte comercial porque é mais habilidoso em negociar projetos com os clientes. Enquanto o terceiro, mais tímido e reservado se dedica ao desenvolvimento dos sistemas. Isso equilibrou a equipe de direção e as funções que desempenham espelham a personalidade de cada um.

Havia, porém, uma latente necessidade de melhorar a complementaridade no campo de atividades. Como faltava a exploração de conceitos nos projetos de consultoria desenvolvidos na Delta, surgiu o processo de decisão estratégica de incluir um novo sócio. A princípio o novo membro trouxe importantes discussões e gerou profícuos e não menos benéficos debates por conta dos diferentes pontos de vista levantados, entretanto não conseguiu trabalhar em sintonia na equipe. Ao longo de dois anos, muitos atritos gerados no trabalho foram redirecionados para o âmbito pessoal; assim, a situação ficou insustentável a ponto de culminar na saída do novo codirigente.

Pode-se evidenciar que houve discordâncias, importante fator de destaque do conflito cognitivo que não pode ser mantido apenas como divergência de pontos de vista entre o novo membro e os codirigentes fundadores. Na verdade, os codirigentes se autointitulavam desenvolvedores, pois todos executavam essa função, fazendo alguma atividade paralela, todavia o codirigente novo adotava uma posição formal de gerente estrategista que contrariava os demais. Esse status criou entre eles uma barreira intransponível a qual levou ao distanciamento na interação.

As fortes discordâncias e as dificuldades dos codirigentes de manter o conflito apenas na dimensão cognitiva levaram ao processo de decisão estratégica de retomar a equipe com os três membros originais. A equipe foi desfeita diante das fortes divergências de estilo de gestão. A confiança na interação entre os codirigentes pareceu ser a marca forte da equipe de direção que fundou a Delta. Contudo, no quarteto evidenciou-se que não fluiu o bastante, pois entre eles não havia liberdade e intimidade o suficiente para despertá-la. O companheirismo de longa data explica o funcionamento à base de conflitos cognitivos da equipe original. 
Desse modo, pode-se dizer que os fatores de destaque do conflito cognitivo analisados acima surgiram nos processos de decisão estratégica e desencadearam mudanças na mentalidade dos codirigentes em relação ao negócio Delta. Pode-se dizer que a aprendizagem em circuito duplo despertada pelos conflitos cognitivos foi a responsável por muitas mudanças significativas nessa PE.

A seguir serão discutidas as evidências desse tipo de aprendizagem.

\subsection{Processos de decisão estratégica: ocorrências de aprendizagem em circuito duplo}

A aprendizagem em circuito duplo está relacionada às seguintes expressões identificadas em cada processo de decisão estratégica: entendimento dos sócios da necessidade de mudar suas vidas profissionais; reconhecimento do fracasso do produto e da alternativa de prestação de serviços; compreensão da necessidade de explorar os serviços prestados e; percepção de que a expansão da empresa precisaria de aprofundamento de teorias seguida de frustração dessa perspectiva.

\subsubsection{Entendimento dos sócios da necessidade de mudar suas vidas profissionais}

No processo de decisão estratégica concernente à criação do produto Delta pode-se constatar a aprendizagem em circuito duplo, expressa por meio da mudança de pensamento coletiva, a qual levou três colegas de trabalho ao entendimento de que precisavam mudar suas vidas profissionais tornando-se donos do próprio negócio.

O primeiro efeito dessa aprendizagem envolveu a conscientização por parte dos codirigentes de que poderiam alterar a circunstância de trabalho desfavorável à qualidade de vida na qual se encontravam. Tal circunstância relacionava-se com a realidade de gestão burocrática e política que passaram a vivenciar na empresa onde exerceram seu trabalho por mais de uma década.

Essa empresa cresceu e adquiriu valores que os codirigentes começaram a questionar fortemente. Ocorreu então na equipe de direção, unida ainda informalmente, uma mudança de pensamento a qual norteou e impulsionou o processo de decisão estratégica de criação do produto Delta. Os codirigentes fundaram o seu negócio amparados por pressupostos éticos e morais que apreciavam na condução de uma empresa.

Contudo, em meio ao processo de criação do produto Delta, experimentaram uma mudança de comportamento em relação ao negócio, outro fator de destaque da aprendizagem em circuito duplo, fruto do questionamento dos pressupostos adotados na empresa que fundaram. A inovação e o processo criativo no desenvolvimento do produto foram uma marca constante no início do funcionamento da Delta, entretanto o produto inovador não trouxe os resultados que os codirigentes esperavam, pois apesar de ter havido repercussão na mídia, o produto não foi aceito no mercado.

Diante disso, aprenderam que mesmo em face de eminente necessidade de mudar suas vidas profissionais, trabalhando em um negócio no qual acreditavam e que por eles foi criado, seria primordial mudar o comportamento em relação ao empreendimento. Tal mudança de comportamento ocorreu muito apoiada na 
concepção de que resolver uma necessidade no mercado de tecnologia da informação seria mais promissor que inventar um produto.

A empresa fundada a partir do forte desejo dos codirigentes de inovar e serem diferentes teve então, nos primeiros meses, uma relevante revisão de pressupostos básicos por contribuir para sua sobrevivência. Tal revisão foi especial na medida em que ajudou os codirigentes a perceberem que a mudança profissional precisaria vir por partes.

\subsubsection{Reconhecimento do fracasso do produto e da alternativa de prestação de serviços}

O processo de decisão estratégica relativo à transição para empresa prestadora de serviços em consultoria envolveu a mudança de pensamento, fator de destaque da aprendizagem em circuito duplo, expressa a partir do reconhecimento do fracasso do produto Delta.

Os codirigentes perceberam que a falta de conhecimento a respeito do mercado de comunicação, no qual o produto deveria ser comercializado, estava dificultando a sua venda. A princípio, acreditavam ser a ideia inovadora suficiente para alavancar os negócios; todavia, eles constataram a premente necessidade de oferecer soluções ligadas à demanda do mercado.

A partir dessa constatação, os codirigentes puderam identificar nos projetos de consultoria uma forma de prestar serviços básicos que seriam facilmente aceitos, e cujo diferencial estaria na transparência e na abertura nas relações com os clientes.

Houve a redefinição de objetivos, outro fator de destaque da aprendizagem em circuito duplo, surgido a partir do questionamento sobre os rumos daquela empresa de produto e do reconhecimento de que por meio dos serviços de consultoria a equipe de direção teria a chance de continuar trabalhando junto. Nesse ponto, mais importante do que ter um produto de sucesso foi manter a empresa e a equipe, fundadas em sólidas bases de respeito.

Os novos objetivos, surgidos diante da revisão de valores, relacionavam-se com o aproveitamento da oportunidade reconhecida na prestação de serviços de consultoria e no seu progressivo aperfeiçoamento. A partir do reconhecimento do fracasso do produto Delta e da evidência de grande valorização de suas consultorias, percebidas como um diferencial, os codirigentes admitiram que esse ramo de atuação poderia ser o mais promissor.

Por fim, no processo de aprendizado, o que Ihes restou foi rever os objetivos e dedicar-se ao entendimento dos processos de serviços em consultoria de sistemas, considerando-se que eles exigiam o relacionamento mais próximo com outras organizações e a pulverização de projetos para não estabelecer relações de dependências com poucos grupos de clientes.

\subsubsection{Compreensão da necessidade de explorar os serviços prestados}

No primeiro ano de transição para empresa de consultoria, houve forte questionamento dos pressupostos vigentes na Delta, a qual foi fundada para vender produtos e se transformou numa organização de prestação de serviços. Esse fator 
de destaque da aprendizagem em circuito duplo decorreu da conscientização por parte dos codirigentes de que a consolidação da empresa ocorreria apenas a partir da evolução nos serviços prestados.

Os codirigentes constataram a necessidade de explorar seus serviços por meio de melhorias na apresentação do sistema, e elas surgiram do reconhecimento de que o design dos softwares desenvolvido era fraco e pouco contribuía com a acessibilidade dos usuários. Em outras palavras, precisavam tornar os sistemas mais fáceis de usar.

A equipe de direção passou por uma importante evolução de mentalidade e questionamento dos pressupostos básicos amparados na concepção de que os serviços em programação dos sistemas eram invisíveis. Foram despertados para a realidade de que a entrega de projetos mais acabados e, portanto, com maior qualidade visual, trariam notoriedade para a Delta, além de ajudarem, inclusive, a agregar valor aos sistemas.

Pode-se evidenciar nesse processo de decisão estratégica, uma mudança de comportamento em relação ao negócio, fator de destaque da aprendizagem em circuito duplo, identificado a partir da constatação de preocupações estéticas, as quais foram traduzidas na busca da entrega dos projetos com refinamento visual e um detalhe a mais, a garantia de que fossem personalizados e bonitos.

Embora inicialmente tenham sido essas as mais evidentes preocupações percebidas nos relatos do codirigente um, pode-se notar o convencimento da equipe sobre o fato de que esse seria mais um diferencial para o serviço "óbvio" por eles oferecido.

A mudança de comportamento se concretizou ainda por meio da revelação visual da qualidade intangível dos projetos de sistemas ali desenvolvidos. Além disso, houve um importante aprendizado, a ponto de procurarem um espaço de atuação para o design, melhorarem a prestação de serviços e repensarem o nível de qualidade almejado para as consultorias.

\subsubsection{Percepção de que a expansão da empresa precisaria de aprofundamento de teorias seguida de frustração dessa perspectiva}

Seguindo uma linha de reavaliação dos serviços prestados, os codirigentes perceberam uma deficiência importante nos processos de desenvolvimento de sistemas. Dessa reavaliação, surgiu um questionamento dos pressupostos vigentes, fator de destaque da aprendizagem em circuito duplo, expresso por meio da percepção de que além de técnicas eles deveriam dominar aspectos conceituais inerentes aos projetos desenvolvidos.

Com a consolidação dos serviços de consultoria, um grupo mais seleto de clientes apareceu, desafiando a capacidade de explicação científica no processo de negociação e esclarecimentos de projetos maiores de consultoria. Os codirigentes identificaram a necessidade de incluir na equipe um profissional dotado de capacidade acadêmica para projetar trabalhos mais complexos.

Entretanto, junto com essa força acadêmica aliada chegaram outros pressupostos. O novo codirigente começou a impor uma dinâmica diferente na condução dos projetos. Tratava-se de estilos de administração muito diferentes, pois 
a equipe de direção da Delta desenvolvia um trabalho "cirúrgico" e pontual no desenvolvimento de sistemas e a abordagem do novo codirigente era oposta, desejava fazer intervenções diferentes em cada projeto. O seu lema era: 'aprender é o mais importante', enquanto a filosofia de trabalho dos codirigentes fundadores estava amparada em entregar o sistema pronto para o cliente.

Além disso, ele priorizava uma clara separação hierárquica entre quem manda e quem executa os projetos e adotava uma postura de gerente estrategista que incomodou os demais sócios. Conforme o relato do codirigente um: "Aqui na Delta nós somos todos desenvolvedores, mesmo os sócios, temos hierarquia zero aqui..."

Pode-se dizer que houve um choque de valores, o qual trouxe à tona outro fator de destaque da aprendizagem em circuito duplo, a redefinição de objetivos. Como a nova equipe de direção não funcionava, ocorreu naturalmente a saída do quarto codirigente e com a equipe original retomada, novos objetivos foram traçados para a Delta. Nas palavras do codirigente dois "o próprio codirigente novo percebeu isso também e tal, então ele decidiu sair da empresa, pra gente isso foi uma das melhores coisas que aconteceu..."

Junto à retomada e reafirmação dos valores da Delta veio a redefinição de objetivos, expressa na ideia de manter a empresa desburocratizada, com abertura e respeito nos diálogos e debates de ideias e maneira prática, focando novamente no óbvio para conduzir os projetos de consultoria, "sem inventar moda".

$\mathrm{Na}$ sequência, as relações entre esses processos de aprendizagem em circuito duplo e os conflitos cognitivos apresentados serão estabelecidas.

\subsection{Relações entre conflito cognitivo e aprendizagem em circuito duplo}

Evidenciou-se que alguns efeitos desses conflitos favoreceram a ocorrência da aprendizagem em circuito duplo por parte dos codirigentes. Constatou-se com a pesquisa que os conflitos cognitivos surgidos na interação entre os codirigentes da Delta exerceram influência significativa nos processos de decisão estratégica estudados.

Cabe destacar que o conflito pode ser benéfico e prejudicial para a eficácia da equipe em processos de decisão estratégica, dependendo do seu tipo, respectivamente cognitivo ou afetivo, como sugerem Amazon et al. (1995), Mooney et al. (2007) e Hjerto e Kuvaas (2017), os quais ainda alertam sobre o seguinte aspecto: as equipes que funcionam são as intuitivamente cientes dos dois tipos. Por estarem conscientes de seus conflitos afetivos e com o fito de evitá-los, assim como estimular apenas os de modalidade cognitiva, na Delta foram desenvolvidos mecanismos tais quais: comunicação aberta, confiança, boa integração e, ao mesmo tempo, foco no cerne das questões a respeito do processo decisório, não se perdendo em questões pessoais.

A confiança, muito associada ao conflito e favorecedora do conflito cognitivo, surgiu como fator marcante e atenuante nas relações das equipes. Pode-se afirmar que essa percepção originou-se da transparência e da reciprocidade nas interações entre os codirigentes da Delta. Assim como nos estudos de Clerkin e Jones (2013), 
nesta pesquisa tornou-se possível incluir questões de confiança como um dos fatores que levaram ao conflito cognitivo.

Importante se faz saber que as relações de confiança conferiram às equipes maior abertura para desafiarem as perspectivas como sugerem Olson et al. (2007). $\mathrm{Na}$ Delta, constatou-se essa abertura, a qual conduziu os codirigentes a questionarem uns aos outros, sem medo de serem ridicularizados ou de receberem qualquer retribuição.

Os resultados da pesquisa demostraram que a confiança baseada em competência no campo de atividade fortaleceu a interação dos codirigentes nos diferentes processos de decisão estratégica. Além de questões de confiança mútua, o respeito que um codirigente tem pelo campo de atividade e campo de competência do outro, em termos de perícia técnica e experiência, muito contribuiu para que os conflitos se mantivessem cognitivos. Cada codirigente debate ideias e opiniões nos processos de decisão estratégica, amparado pelo conhecimento angariado em seu setor de atuação na empresa onde se tornou especialista em analisar e por isso, acumulou base para discutir e tornar-se o representante.

As equipes de direção bem sucedidas ao longo do tempo agem dessa forma e revelam uma postura proativa, como sugerido por Behfar et al (2011), antecipando a necessidade de resolver os seus conflitos. De Dreu (2008) defendeu que as funções positivas do conflito podem de fato ser encontradas. No entanto, destacou que apenas em um conjunto extremamente restrito de casos isso seria possível. Ainda argumentou o autor que, se as consequências positivas do conflito cognitivo surgem apenas em circunstâncias muito específicas, elas são a exceção.

Parece que a Delta se enquadra nesse conjunto especial, sendo ela a referenciada exceção à regra. Nesta $\mathrm{PE}$, há fortes indicações qualitativas de que os processos de decisão estratégica se basearam no envolvimento, na discussão e na participação dos codirigentes (HJERTO; KUVAAS, 2017). Como Woods (2012) e De Wit et al. (2012) afirmam: o conflito é um combustível que promove novas soluções estratégicas. A grande abertura ao diálogo, constatada nessa PE, é um resultado que se alinha às perspectivas desses autores.

Os conflitos cognitivos dotaram os codirigentes da capacidade de autoquestionamento, aspecto essencial para o aprendizado em circuito duplo. A partir desses processos de revisão dos pressupostos básicos vigentes, inclusive com questionamentos sobre a pertinência de algumas normas de funcionamento das PEs, tornaram-se aptos a aprender a aprender, conforme defende Argyris e Schön (1978).

A partir dos processos de detecção e correção de possíveis erros de conduta e do aproveitamento deles para incentivar seu crescimento, os codirigentes conseguiram perceber e intervir no sistema de funcionamento de seus negócios de uma forma dinâmica e adaptativa.

Os processos de aprendizagem em circuito duplo ocorreram apenas porque na Delta se encorajou a abertura ao diálogo, assim como foram aceitos os debates de ideias e as discordâncias. Houve ali suficiente interação entre os codirigentes para suportarem pontos de vistas distintos e interpretações divergentes. Análises de possibilidades favoreceram a correção de erros detectados. 
Contatou-se que essa interação tornou-se natural e espontaneamente despertou processos de aprendizagem em circuito duplo, os quais foram ocorrendo a partir do reconhecimento dos codirigentes de que o desenvolvimento da empresa dependia de uma revisão nos conceitos e nas práticas, embora no passado eles tenham permitido avanços. Tal aprendizagem significou uma reflexão crítica, a qual os codirigentes realizaram nos processos de decisão estratégica com vistas a reverem seus comportamentos. Pode-se dizer que ela desencadeou mudanças profundas de pensamento e, consequentemente, de ações, conforme explicam Argyris e Schön (1978).

Nos processos de decisão estratégica, evidenciou-se que os codirigentes utilizaram muito mais a aprendizagem em circuito duplo como combustível para deliberá-los do que procedimentos racionais analíticos e formais. Assim, interpretouse que a maneira de aprender e desenvolver os processos de decisão na Delta foi principalmente por meio da aprendizagem, como sugerido nos estudos de Wyer et al. (2000).

Os resultados deste estudo demonstraram que a aprendizagem em circuito duplo resultou em alterações de comportamento e ainda ofereceu oportunidade para os codirigentes se comportarem de forma diferente em relação aos negócios. Tais resultados observados nas análises dos dados vão ao encontro dos argumentos de Enakem e Smallbone (2007). Em seu estudo, os autores afirmaram que aprender não necessariamente resulta em alterações imediatas de comportamento, mas pode oferecer o potencial para os indivíduos se comportarem de maneira diferente.

Há maneiras padronizadas que determinaram como os codirigentes aprenderam nos processos de decisão estratégica. Nas PEs estudadas foi por meio do conhecimento compartilhado informalmente e das trocas de experiências, aspectos desencadeados nos conflitos cognitivos surgidos. Na presente pesquisa, se tornou evidente que a aprendizagem foi direcionada pelo conflito cognitivo, ajudou a questionar os pressupostos vigentes e impulsionou a renovação estratégica, assim como defendeu Woods (2012). Por consequência, muitos processos de decisão estratégica se pautaram na perspectiva artesanal de estratégia, no "aprender fazendo" e não em um modelo racional de planejamento estratégico.

No modelo racional, os processos de decisão estratégica são frequentemente conduzidos por um único indivíduo, como esclarecem Brouthers et al. (1998). Na Delta, isso não ocorreu, pois as equipes trabalharam conjuntamente para melhor decidir e, inclusive os sócios minoritários em participação societária encontraram a possibilidade de participarem como os majoritários, devido à competência técnica revelada. Nela, o conflito cognitivo tornou-se elemento importante para a aprendizagem em estratégia e possibilitou aos codirigentes tomar decisões mais fundamentadas. Embora menos amparadas por procedimentos racionais e analíticos, seriam mais pautadas na troca de experiência, compartilhamento e aprendizagem coletiva.

Por isso, é inadequado tomar emprestado o conhecimento de teorias orientadas para grandes organizações no estudo do processo de decisão estratégica das PEs. Nelas, tais processos se concentram em poucos indivíduos; além disso, não há recursos ou setores para realizar análises aprofundadas, por exemplo, sobre 
o ambiente externo. Isso dificulta procedimentos formais de decisão estratégica e o resultado é equivalente ao constatado na Delta, processos de decisão estratégica menos complexo, com necessidades menores de coordenação e comunicação; e ao mesmo tempo, mais centralizado entre os codirigentes. Assim como nos estudos de Brouthers et al. (1998) e Liberman-Yaconi et al. (2010), no presente trabalho também se chegou à conclusão de que os processos de decisão estratégica das PEs não podem ser compreendidos à luz de modelos racionais desenvolvidos para explicar tais processos nas grandes organizações.

$\mathrm{Na}$ Delta, à medida que os codirigentes questionaram suas ações e os rumos que a PE vinha seguindo, houve um redirecionamento. Eles debateram sobre novas possibilidades, discutiram alternativa de direção e terminaram por desafiar os pressupostos vigentes, criando novas regras e valores para condução de seus negócios. Esse redirecionamento que 0 conflito cognitivo impulsionou, especialmente nos momentos de decisão estratégica, materializou a aprendizagem em circuito duplo, tornando-a mais importante que processos racionais e formalizados de decisão estratégica.

\section{Considerações finais}

Este trabalho procurou estudar os processos de decisão estratégica realizados por codirigentes na equipe de direção da PE Delta. Os dados obtidos nesta pesquisa mostraram que a decisão estratégica se origina de processos de aprendizagem em circuito duplo (ARGYRIS; SCHON, 1978) e de conflitos cognitivos (WOODS, 2012), surgidos na PE estudada. Foram investigadas as etapas e os momentos cruciais dos processos de decisão a fim de se averiguar o comportamento dos codirigentes. Analisaram-se decisões estratégicas que, segundo relato dos mesmos, resultaram em uma descontinuidade clara nos rumos da empresa.

Consistente com outras pesquisas sobre gestão estratégica de PEs, o estudo identifica a aprendizagem em circuito duplo e o conflito cognitivo como aspectos mais preponderantes nos processos de decisão estratégica desse tipo de organização, em detrimento do planejamento estratégico formal. Diante da evidência de que a abordagem de Mintzberg sobre as estratégias emergentes, a qual explica a aprendizagem em estratégia, já foi muito explorada, buscou-se a compreensão a respeito dos processos de decisão por meio da abordagem de aprendizagem em circuito duplo proposta por Argyris e Schön (1978).

Juntos, argumentos teóricos e constatações empíricas da pesquisa representam um passo a mais para conhecer como ocorrem processos de decisão estratégica em PEs. Pode-se dizer que na equipe de direção estudada tais processos ocorreram especialmente carregados de conflitos, pois eles são parte importante do funcionamento dela.

A aprendizagem foi constatada como um processo de evolução em meio aos conflitos surgidos e permitiu extrair o melhor deles, ou seja, sua dimensão cognitiva. Pode-se afirmar que, nos últimos cinco anos, a capacidade dos codirigentes de aprenderem coletivamente em circuito duplo proporcionou à Delta uma grande capacidade de resposta às oportunidades e ameaças a ela apresentadas. 
Tornou-se muito evidente que os padrões dos processos de decisão estratégica nessa PE estão apoiados em conflitos cognitivos e em comportamentos que se baseiam não no pensamento analítico, mas na reflexão dos valores, num processo de aprendizagem em circuito duplo.

Descobriu-se que muitas decisões estratégicas foram tomadas a partir de um processo de revogação de pressupostos básicos vigentes em processos decisórios que contrariaram normas existentes e alguns valores dos codirigentes. É importante ressaltar que a aprendizagem em circuito duplo envolveu os codirigentes nos diferentes processos de decisão estratégica em uma mudança de valores e atitudes consolidada ao longo do tempo. Devido ao comportamento pré-existente, muitas vezes, em contraposição à flexibilidade requerida para se rever normas de funcionamento, a interação dos codirigentes fez a diferença. Notou-se que um influenciava o outro, num processo de aprendizagem compartilhada que permitiu detectar e corrigir os erros de conduta na direção da PE e o aproveitamento desses erros para incentivar o crescimento dela.

Os processos de aprendizagem em circuito duplo na equipe de direção dotaram a Delta da capacidade de aprender; em outras palavras, da capacidade de questionar as normas pré-definidas. Isso, de acordo com informações provenientes de conversas estratégicas ou trocadas em debates de ideias frente aos processos de decisão estratégica.

Os conflitos cognitivos por sua vez, dotaram os codirigentes da capacidade de autoquestionamento, aspecto essencial para a identificação dos erros e a consequente ocorrência da aprendizagem em circuito duplo. A partir desses processos de revisão dos pressupostos básicos vigentes e questionamento da pertinência de alguns aspectos concernentes ao comportamento em relação ao negócio, tornaram-se aptos a aprender a aprender.

Conclui-se que encontrar conflito nos processos de decisão estratégica envolvidos pela aprendizagem, foi uma construtiva consequência. Especialmente porque ele foi usado para facilitar a troca de informações entre os codirigentes, habilidosos em se expressarem e aceitarem posições contraditórias e opiniões dos outros. Isso terminou por resultar na aprendizagem em circuito duplo.

Por fim, cabem ainda algumas considerações a respeito de limitações, sugestões e implicações práticas do estudo. O desenvolvimento deste trabalho traz algumas limitações, as quais são interpretadas da seguinte forma: a primeira limitação refere se à dependência de dados obtidos por meio de autorrelato dos processos de decisão estratégica ocorridos no passado, embora o estudo os caracterize e evidencie como foram conduzidos. Realizar em retrospectiva a análise de como os dirigentes conduziram-nos pode ter gerado um viés para relatos mais amparados na racionalidade nesses processos.

Em termos de implicações práticas acredita-se que o estudo a respeito dos processos de decisão estratégica em uma PE enriquece o conhecimento sobre os mecanismos que conduzem esse tipo de organização a participar na vida econômica do país e contribui para o crescimento e a prosperidade da sociedade. 


\section{Referências}

ARGYRIS, C. A life full of learning. Organization Studies, v. 24, n.1, p.1178-1192, 2003.

ARGYRIS, C.; SCHÖN, D. A. Organizational Learning: a Theory of Action Perspective. Addison-Wesley Series on Organization Development, 1978.

BANDEIRA-DE-MELLO, R. Softwares em pesquisa qualitativa. In: Pesquisa Qualitativa em Estudos Organizacionais: paradigmas, estratégias e métodos. São Paulo: Editora Saraiva, p. 97-118, 2006.

BEHFAR, K. J.; MANNIX, E. A.; PETERSON, R. S.; TROCHIM, W. M. Conflict in small groups: The meaning and consequences of process conflict. Small Group Research, v. 42, n. 2, p. 127-176, 2011.

BRESMAN, $\mathrm{H}$. Changing routines: A process model of vicarious group learning in pharmaceutical R\&D. Academy of Management Journal, v. 56, n. 1, p. 35-61, 2013.

CHASTON, I.; BADGER, B.; SADLER-SMITH, E. Organizational learning: an empirical assessment of process in small UK manufacturing firms. Journal of Small Business Management, v. 39, n. 2, p. 139-151, 2001.

DE DREU, C. K. W. The virtue and vice of workplace conflict: Food for (pessimistic) thought. Journal of Organizational Behavior, v. 29, n. 1, p. 5-18, 2008.

EISENHARDT, K. M.; KAHWAJY, J. L.; BOURGEOIS, L. J. How management teams can have a good fight. Harvard Business Review, v. 75, p. 77-86, 1997.

EKANEM, I.; SMALLBONE, D. Learning in Small Manufacturing Firms The Case of Investment Decision-making Behaviour. International Small Business Journal, v. 25, n. 2, p. 107-129, 2007.

ESCRIBÁ-ESTEVE, A.; SANCHEZ-PEINADO, L.; SANCHEZ-PEINADO, E. The influence of top management teams in the strategic orientation and performance of small and Medium-sized enterprises. British Journal of Management, v. 20, n. 4, p. 581-597, 2009.

FULLER-LOVE, N. Management development in small firms. International Journal of Management Reviews, v. 8, n. 3, p.175-190, 2006.

GREENE, P. G.; BRUSH, C. G.; BROWN, T. E. Resources in small firms: an exploratory study. Journal of Small Business Strategy, v. 8, n. 2, p. 25-40, 2015.

GUNDERMAN, R. B.; CHAN, S. Where Is the Action in Organizational Learning? Radiology, v. 242, n. 3, p. 650-653, 2007.

HAMBRICK, D. Fragmentation and the other problems CEOs have with their top management teams. California Management Review, v. 37, n. 1, p. 110-127, 1995. 
HJERTO, K.; KUVAAS, B. Burning hearts in conflict: new perspectives on the intragroup conflict and team effectiveness relationship. International Journal of Conflict Management, v. 28, n. 1, 18-29, 2017.

IBRAHIM, A. B. Strategy Types and Small Firms' Performance An Empirical Investigation. Journal of Small Business Strategy, v. 4, n. 1, p. 13-22, 2015.

JEHN, K. A.; GREER, L.; LEVINE, S.; SZULANSKI, G. The effects of conflict types, dimensions, and emergent states on group outcomes. Group Decision and Negotiation, v. 17, n.6, p. 465-495, 2008.

KATZENBACH, J. R.; SMITH, D. K. The Discipline of Teams What makes the difference between a team that performs and one that doesn't? Harvard Business Review, July-August, 2005.

LIBERMAN-YACONI, L.; HOOPER, T.; HUTCHINGS, K. Toward a model of understanding strategic decision-making in micro-firms: exploring the Australian information technology sector. Journal of Small Business Management, v. 48, n. 1, p. 70-95, 2010.

LIMA, E. Les liens entre représentations entrepreneuriales et vision partagée : étude d'équipes de dirigeants de PME. Revue Internationale de Psychosociologie, v.18, n. 1, p. 199-225, 2012.

LOUGHRY, M. C.; AMASON, A. Why won't task conflict cooperate? Deciphering stubborn results. International Journal of Conflict Management, v. 5, n. 4, p. 333358, 2014.

LUBATKIN, M. H.; SIMSEK, Z.; LING, Y.; VEIGA, J. F. Ambidexterity and performance in small-to medium-sized firms: The pivotal role of top management team behavioral integration. Journal of management, v. 32, n. 5, p. 646-672, 2006.

MATTIA, A. Utilizing a Learning Loop Framework in IS Security. International Journal of Business and Social Science, v. 2, n. 21, p. 22-32, 2011.

MAZZAROL, T.W.; REBOUD, S. The strategic management process. IN: The Strategy of Small Firms. Edward Elgar Publishing Ltd, Cheltenham UK, Northampton, MA, USA, 2009.

MELLO, A. L.; DELISE, L. A. Cognitive Diversity to Team Outcomes The Roles of Cohesion and Conflict Management. Small Group Research, v. 46, n. 2, p. 204-226, 2015.

MOONEY, A. C.; HOLAHAN, P. J.; AMASON, A. C. Don't take it personally: Exploring cognitive conflict as a mediator of affective conflict. Journal of Management Studies, v. 44, n. 5, p. 733-758, 2007.

OLSON, B. J.; PARAYITAM, S.; BAO, Y. Strategic decision making: The effects of cognitive diversity, conflict, and trust on decision outcomes. Journal of Management, v. 33, n. 2, p. 196-222, 2007. 
SERVIÇO BRASILEIRO DE APOIO ÀS MICRO E PEQUENAS EMPRESAS. Anuário do trabalho na micro e pequena empresa: 2010-2011. 4. Ed, São Paulo: SEBRAE; DIEESE, 2011.

TJOSVOLD, D.; WONG, A. S.; FENG CHEN, N. Yi. Constructively managing conflicts in organizations. Annual Review of Organizational Psychology and Organizational Behavior, v. 1, n. 1, p. 545-568, 2014.

VAN WOERKOM, M.; VAN ENGEN, M. L. Learning from conflicts? The relations between task and relationship conflicts, team learning and team performance. European Journal of Work and Organizational Psychology, v.18, n. 4, p. 381404, 2009.

WATKINS, K. E.; SHINDELL, T. J. The learning and transforming through action science. New Directions for Adult and Continuing Education, v.4, n. 63, p. 43-55, 1994.

WEINGART, L. R.; BEHFAR, K. J.; BENDERSKY, C.; TODOROVA, G.; JEHN, K. A. The directness and oppositional intensity of conflict expression. Academy of Management Review, v. 40, n. 2, p. 235-262, 2015.

WOODS, J. G. Using cognitive conflict to promote the use of dialectical learning for strategic decision-makers. Learning Organization, v.19, n. 2, p. 134-147, 2012.

WYER, P.; MASON, J.; THEODORAKOPOULOS, N. Small business development and the "learning organisation". International Journal of Entrepreneurial Behavior \& Research, v. 6, n. 4, p. 239-259, 2000.

YIN, R.K. Estudo de caso: planejamento e métodos. 4. ed. Porto Alegre: Bookman, 2010.

YOON, W.; KIM, S. J.; SONG, J. Top management team characteristics and organizational creativity. Review of Managerial Science, v. 10, n. 4, p. 757-779, 2016.

WOLFF, J.; PETT, T. L.; RING, J. K. Small firm growth as a function of both learning orientation and entrepreneurial orientation: an empirical analysis. International Journal of Entrepreneurial Behavior \& Research, v. 21, n. 5, p. 709-730, 2015. 